\title{
Classification by multiple regression - a new approach towards the classification of extremes
}

\author{
Wolfgang Enke, Arne Spekat \\ Climate \& Environment Consulting GmbH, David-Gilly-Straße 1, 14469 Potsdam, Germany, e-mail: wolfgang.enke \\ @cec-potsdam.de, arne.spekat@cec-potsdam.de
}

\section{Frank Kreienkamp}

Deutscher Wetterdienst, Michendorfer Chaussee 23, 14473 Potsdam, Germany, e-mail: frank.kreienkamp@dwd.de

\begin{abstract}
There are numerous algorithmic classification methods that attempt to address the connections between different scales of the atmosphere, such as EOFs, clustering, and neural nets. However, their relative strength lies in the description of the mean conditions, whereas extremes are poorly covered by them.

A novel approach towards the identification of linkages between large-scale atmospheric fields and local extremes of meteorological parameters is presented in this paper. The principle is that a small number of objectively selected fields can be used to circumscribe a local meteorological parameter by way of regression. For each day, the regression coefficients form a kind of pattern which is used for a classification based on similarity. As it turns out, several classes are generated which contain days that constitute extreme atmospheric conditions and from which local meteorological parameters can be computed, yielding an indirect way of determining these local extremes just from large-scale information.

The range of applications is large. (i) Not only local meteorological parameters can be subjected to such a regressionbased classification procedure. It can be extended to extreme indicators, such as threshold exceedances, yielding on the one hand the relevant atmospheric fields to describe those indicators, and on the other hand grouping days with "favourable atmospheric conditions". This approach can be further extended by investigating networks of measurement stations from a region and describing, e.g., the probability for threshold exceedances at a given percentage of the network. (ii) The method can not only be used as a filtering tool to supply days in the current climate with extreme conditions, identified in an objective way. The method can be applied to climate model projections, using the previously found parameter-specific combinations of atmospheric fields. From those fields, as they constitute the modelled future climate, local time series can be generated which are then analysed with respect to the frequency and magnitude of future extremes.

The method has sensitivities (i) due to the degree to which there are connections between large-scale fields and local meteorological parameters (measured, e.g., by the correlation) and (ii) due to the varying quality of the different fields (geopotential, temperature, humidity etc.) projected by the climate model.
\end{abstract}

Keywords: empirical-statistical downscaling, regression analysis, climate analysis, climate projections, meteorological extremes

Submitted 30 July 2015, revised 5 February 2016, accepted 24 March 2016

\section{Introduction}

Climate change and meteorological extremes in particular pose considerable risks for humans and natural systems (Cramer et al. 2014; IPCC 2014). It is also a large research challenge to understand their nature as well as forecast or project their development over time (Eade et al. 2012; Hamilton et al. 2012; Dole et al. 2013; Pepler et al. 2015). Attempts to do this are made using, for example, extreme value analysis (EVA), which aims at a description of the behavior of probability density distributions' tails using particular mathematical functions (see, e.g., Svens- son, Jones 2010, or Dalelane, Deutschländer 2013). However, rather long data series are required to apply those methods. Using a method which links atmospheric states and local meteorological extremes appears to be a feasible alternative. This is an entirely different approach since the extremes are identified as atmospheric conditions with a high degree of distinctiveness (by way of classification) prone to yielding an adequate description of a local meteorological parameter, called the predictand. The method makes no assumptions as to extreme characteristics of the time series of the local meteorological parameter. The local extremes are merely an outcome of the identification of 
the classification of "extreme-prone" atmospheric conditions. It is a further advantage of the method that it can, however, be applied in conjunction with extreme regional conditions by selecting an appropriate predictand, e.g., the surpassing of a certain extreme threshold - see also the note at the end of Section 1.4. Some background and a rationale are given in the following sections of the introduction.

\subsection{Context - patterns and classification}

The aim of the authors is to develop an alternative strategy to achieve a classification of atmospheric structures. But before this will be addressed, some remarks on "standard" approaches needs to be made. The broader context is synoptic climatology, which, according to Glickman (2000), deals with "...the study of climate from the perspective of atmospheric circulation, with emphasis on the connection between circulation patterns and climatic differences « on a hemispheric or regional scale. It is common to »determine distinct categories of synoptic weather patterns and then to assess statistically the weather condition associated with these patterns«. In essence, synoptic climatology is about identifying linkages between the large scale, i.e., on the order of one to several thousand $\mathrm{km}$, and the regional scale, i.e., on the order of several ten to several hundred $\mathrm{km}$.

This is rooted in two paradigms:

- There are semi-stable patterns within atmospheric structures which allow for such a classification;

- The atmospheric states assembled in any of the classes are relatively homogeneous.

Consequently, it is meaningful to apply pattern identification methods and use the ensuing "subdivision"/classification of atmospheric states for pattern-specific analyses. This is corroborated by a further observation (Dzerdzeevskii 1963, quoted in Barry, Perry 1973): »...all changes in temperature and precipitation ... are connected with changes in frequency and duration of large-scale circulation patterns «. Further methodological groundwork can be found, e.g., in Chapters 3B and 3C of Barry and Perry (1973). In order to match the temporal scale of expected atmospheric structures and available data, daily resolution will be favoured in the methodology.

Ideally, all classes should be as distinct as possible, exhibiting a maximum of dissimilarity, whereas an individual class should be as uniform as possible, i.e., its members should exhibit a maximum of similarity. In order to achieve such a classification there are two fundamental approaches (Yarnal 1993), which are summarised in the next two subsections.

\subsection{The Circulation-to-Environment (C2E) strategy}

This is by far the most frequently applied strategy. It relies on morphological similarities between features in largescale atmospheric fields, e.g., the geopotential, which are used to build the classes. The step towards the regional climate (the environment) is subsequently made by analysing regional meteorological parameters, such as surface temperature, precipitation, etc., in grouped or stratified form, i.e., jointly for the individual classes.

The determination of which fields are similar to each other can be carried out in a manual-empirical way, i.e., by expert assessment. Well-introduced classifications such as the Großwetterlagen (Hess, Brezowsky 1952; Gerstengarbe, Werner 2005) or the British Isles Weather Types (Lamb 1972) are of the manual-empirical kind.

However, there are numerous multivariate mathematical methods through which a classification can be achieved in an automated way (Barry, Perry 1973). These encompass Empirical Orthogonal Functions (EOFs), clustering, neural nets and so forth. A COST Action (COST733 - Harmonization and Applications of Weather Types Classifications for European Regions) took place between 20062011, aiming at an intercomparison of atmospheric pattern classification methods. For more detail the reader is referred to, e.g., Huth et al. (2008), Philipp et al. (2010) and Beck, Philipp (2010). In the individual classification methods, as they were compared in the COST733 Action, the patterns are either determined from single atmospheric fields, e.g., surface pressure, geopotential, temperature, or a combination of those fields. A great deal of explained variance, when compared to non-classified data, can be accomplished when stratifying regional data according to the large-scale C2E classes (cf., e.g. Enke, Spekat 1997).

\subsection{The Environment-to-circulation (E2C) strategy}

This classification strategy takes a route that is opposite to the $\mathrm{C} 2 \mathrm{E}$ strategy. It first focuses on the regional scale by identifying the range of a meteorological parameter, e.g., temperature or precipitation. This range is then divided into a number of classes to which the days are assigned. The step from the regional scale (the environment) to the large scale (the circulation) is made by building classwise composites of the atmospheric fields using the days in each class. The principle is described and visualised in Enke et al. (2005) and Spekat et al. (2010).

E2C classifications are rather infrequently used. One instance, however, constitutes the building block of a statistical downscaling method called WETTREG (German: Wetterlagen-basiertes Regionalisierungsverfahren. English: Weather 
pattern-based regionalization method) which has been applied in numerous climate change and climate impact studies for German Federal and State environment agencies, published, e.g., in Kreienkamp et al. (2009, 2011a, b).

It should be noted that E2C-based methods by their very nature need to be adapted to local conditions, whereas automated C2E classifications as mentioned in Subsection 1.2 apply a methodology which is unified, regardless of regional particularities. The price for the somewhat "universal" C2E approach is their rather limited ability to describe regional climates, e.g., by way of forming classes that separate well value ranges of a regional meteorological parameter, as shown in Spekat et al. (2010).

\subsection{Classification, future climate and extremes}

Classification is a valid strategy in synoptic climatology, particularly when it is applied to link large-scale and local climate behaviour. It is instrumental in reducing variance in regional climate time series and constitutes an approach to producing meaningful "subdivisions" of the regional climate which are a vantage point for further analyses. Shifts in the class frequencies can also be investigated to assess the properties of a changing climate. This encompasses studies of the class frequency distribution's development over time (e.g. Cahynová, Huth 2009).

Applying classification to climate projections leads to insights concerning possible future changes in the atmospheric circulation and - generally following Dzerdzeevskii's hypothesis (cf. Subsection 1.1) - leads to assessments of future climate behaviour.

However, the strength of descriptions and climate projections combined with classifications lies within the realm of the average climate. Some of the findings of the COST733 Action point in that direction:

- In order to capture extremes by classification, a high number of classes are required. This creates a dilemma because a high number of classes also raise questions of representativeness; are 30 classes justified when decadal daily data are being classified?

- It may not be feasible to assume that there is the one atmospheric pattern which governs all extremes; although they are by definition rare events, extremes might still be found in conjunction with different patterns.

Within the frame of the WEREX-Study (German: Wetterlagen, Regressionen und Extreme; English: Weather patterns, regression and extremes) for the State Environment Agency of Saxonia, an attempt was made to use the classes produced by different classification methods as proxies for extremes. This means that the following conjecture was applied: Whenever a day of class X occurs it is assumed that it is also an extreme, according to an extreme indicator $y$, e.g., an ice day with a maximum temperature below $0^{\circ} \mathrm{C}$. Then, contingency tables were determined containing the joint occurrence of $x$ and $y$ as well as the cases $x$ but (not $y$ ) and (not $x$ ) but $y$ as well as neither $x$ nor $y$. Using verification statistics, skill scores were computed. Several classifications (subjective, automated, E2C, C2E) were tested and the conclusion was (Kreienkamp et al. 2011b) that extremes cannot be skillfully captured by "standard" classifications, regardless of their approach.

A note on extremes: On the one hand, some of the meteorological parameters are themselves extremes, such as daily maximum or minimum temperature (see list in Section 2). So it may be feasible to apply a classification on those parameters to identify particularly relevant conditions. On the other hand, there is ongoing activity by WMO to define and disseminate a set of relevant extreme indicators (Klein Tank et al. 2009) - some are in conjunction with a variable being above or below a defined value (threshold-based) and some are in conjunction with a value belonging to a defined portion of the value range encountered in a time series (percentilebased). The consequence is that the time series to be analysed is transformed from containing the meteorological parameter itself to a binarised form, i.e., 1: criterion is met, and 0: criterion is not met. When dealing with two-dimensional data structures, such as the study of data from a network of stations or an array of grid points, there is an added possibility: Looking at an area and determining for each day the share of stations for which a certain criterion has been met.

\subsection{A different look at patterns - a potential way out concerning extremes}

In the previous subsections of the introduction we established the usefulness of atmospheric patterns and classification and yet noticed that they are more tailored to describing average climate conditions and less so the extremes. It is therefore proposed that we look in a different manner at the concept of what a pattern is describing.

The linkage between large-scale patterns and regionalscale meteorological variables can be determined by way of a multiple regression. The aim is to indirectly describe, e.g., the regional temperature through a set of large-scale fields, weighted and scaled by regression coefficients. So for each day a "setting" of regression coefficients is achieved, which can be interpreted as a vector.

Then, the concept of similarity is applied with respect to the "settings" of those regression coefficients, meaning that a class is formed by a pattern of how the regression coefficients are arranged for individual days. The pattern construction method of choice is k-means clustering (Mac- 
Queen 1967) which is widely applied in synoptic climatology (see e.g., Barry, Perry 1973; Cuell, Bonsal 2009).

It should be expected that such a methodology - screening regression followed by $k$-means clustering - isolates extremes in the clustering's starting partition and groups similar events accordingly. Kreienkamp et al. (2014) show an application with respect to the occurrence of convective events in the German Federal State of Hesse.

\subsection{Structure of this paper}

Following this introduction the paper deals with the data requirements in Section 2. Section 3 contains a description of the method and Section 4 presents some results with emphasis on extremes and extreme indicators. A summary and outlook is given in Section 5.

\section{Data}

The methodology links regional scale meteorological parameters and large scale atmospheric variables. Therefore, in order to develop these linkages, two kinds of data are necessary:

- Daily time series of surface measurements at climate stations for the time frame 1971-2010. These are supplied for this study by the German Weather Service (DWD) for 36 stations in the German Federal State of Hesse (see Table 1). They include extreme-relevant parameters:

- Minimum temperature (TN);

- Daily average temperature (TM);

- Maximum temperature (TX);

- Precipitation (RR);

- Water vapour pressure (DD);

- Daily average of wind velocity (FF);

- Re-Analysis data for a "climatology of the free atmosphere". The NCEP/NCAR Re-Analyses (Kalnay et al. 1996) offer coverage of the desired time frame. Fields of geopotential, temperature and humidity at several height levels were extracted and an array of 60 fields in total was derived (see Table 2). This is the so-called pool of potential predictors used in the screening regression analysis (see Subsection 3.1). They are mapped onto a field of $21 \times 21$ equidistant grid points, $110 \mathrm{~km}$ apart.

In the case of the assessment of the future development of extremes, simulations by a General Circulation Model (GCM) are required.

The majority of the atmospheric parameters, given in Table 2, are self-explanatory. In the subsections of Appen$\operatorname{dix} \mathrm{A}$, some of the others are briefly described. An example
Table 1. List of the 36 climate stations used for this study

\begin{tabular}{|c|c|c|c|c|}
\hline No. & Name & 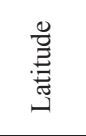 & 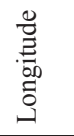 & 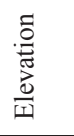 \\
\hline 1 & ALSFELD-EIFA & 50.75 & 9.35 & 300 \\
\hline 2 & BEERFELDEN & 49.57 & 8.97 & 450 \\
\hline 3 & BIEDENKOPF & 50.92 & 8.53 & 349 \\
\hline 4 & BURGWALD-BOTTENDORF & 51.03 & 8.82 & 293 \\
\hline 5 & COELBE_KR_MARBURG & 50.85 & 8.77 & 182 \\
\hline 6 & DILLENBURG & 50.73 & 8.27 & 314 \\
\hline 7 & ESCHWEGE & 51.18 & 10.07 & 170 \\
\hline 8 & FRANKFURT_M (FLUGW.) & 50.05 & 8.60 & 112 \\
\hline 9 & FULDA & 50.53 & 9.68 & 255 \\
\hline 10 & GEISENHEIM & 49.98 & 7.95 & 110 \\
\hline 11 & GERNSHEIM & 49.77 & 8.48 & 90 \\
\hline 12 & GIESSEN_WETTENB & 50.60 & 8.65 & 203 \\
\hline 13 & GILSERBERG-MOISCHEID & 50.97 & 9.05 & 340 \\
\hline 14 & GREBENHAIN-HERCHENHAIN & 50.48 & 9.27 & 608 \\
\hline 15 & HERSFELD_BAD & 50.85 & 9.73 & 272 \\
\hline 16 & HOFGEISMAR-BEBERBECK & 51.53 & 9.48 & 242 \\
\hline 17 & HOMBERG & 50.73 & 9.00 & 250 \\
\hline 18 & KASSEL & 51.30 & 9.45 & 231 \\
\hline 19 & KL_FELDBERG_TS & 50.22 & 8.45 & 826 \\
\hline 20 & LIMBURG_LAHN-OFFHEIM & 50.42 & 8.07 & 185 \\
\hline 21 & LINDENFELS-WINTERKAS & 49.72 & 8.78 & 445 \\
\hline 22 & MELSUNGEN-BUERSTOSS & 51.13 & 9.52 & 254 \\
\hline 23 & NAUHEIM_BAD & 50.37 & 8.77 & 142 \\
\hline 24 & NEUKIRCHEN-HAUPTSCH & 50.90 & 9.40 & 500 \\
\hline 25 & NIDDERAU-WINDECKEN & 50.23 & 8.90 & 180 \\
\hline 26 & SCHAAFHEIM-SCHLIERBACH & 49.92 & 8.97 & 155 \\
\hline 27 & SCHOTTEN & 50.50 & 9.12 & 265 \\
\hline 28 & SONTRA & 51.07 & 9.93 & 265 \\
\hline 29 & WAHLSBURG-LIPPOLDSBERG & 51.62 & 9.58 & 176 \\
\hline 30 & WALDEMS-REINBORN & 50.27 & 8.37 & 380 \\
\hline 31 & WARTENBERG-ANGERSBACH & 50.63 & 9.45 & 270 \\
\hline 32 & WASSERKUPPE & 50.50 & 9.95 & 921 \\
\hline 33 & WIESBADEN (SUED) & 50.07 & 8.27 & 147 \\
\hline 34 & WILDUNGEN_BAD & 51.10 & 9.12 & 310 \\
\hline 35 & WILLINGEN_UPLAND & 51.30 & 8.60 & 580 \\
\hline 36 & WITZENHAUSEN & 51.35 & 9.85 & 133 \\
\hline
\end{tabular}

for the reconstruction of a predictand by way of a regression using four predictors is given in Appendix B.

\section{Method Description}

The method presented in this paper contains elements of the Circulation to Environment strategy (cf. Subsection 1.2) since it defines structures in a morphological way and classifies the data according to similarity/dissimilarity in these structures. The innovation lies in the novel concept of "structure" which does not analyse the placement of steering vortices in the atmosphere (as the established 
Table 2. List of the potential predictor fields used in the screening regression analysis. A number of them are described in the Appendix

\begin{tabular}{|c|l|l|}
\hline No. & Field & Level(s) \\
\hline $1-4$ & Geopotential & $1000,850,700,500 \mathrm{hPa}$ \\
\hline $5-6$ & Temperature & $850,500 \mathrm{hPa}$ \\
\hline $7-8$ & Relative Humidity & $850,500 \mathrm{hPa}$ \\
\hline $9-11$ & Horizontal Geopot. Diff. N/S & $850,700,500 \mathrm{hPa}$ \\
\hline $12-14$ & Horizontal Geopot. Diff. E/W & $850,700,500 \mathrm{hPa}$ \\
\hline $15-18$ & Vorticity & $1000,850,700,500 \mathrm{hPa}$ \\
\hline $19-21$ & Thickness & $1000 / 850,1000 / 700$, \\
\hline 22 & Vertical Temp.-Difference & $850-700 \mathrm{hPa}$ \\
\hline $23-25$ & Horizontal Streamline-Diff. & $1000,850,700 \mathrm{hPa}$ \\
\hline 26 & Frontal angle after Margules & - \\
\hline 27 & Lability index Showalter & - \\
\hline 28 & Lability index Enke (dry) & - \\
\hline 29 & Lability Enke (humid) & - \\
\hline $30-32$ & Gradient & $1000,850,700 \mathrm{hPa}$ \\
\hline $33-34$ & Absolute Humidity & $850,700 \mathrm{hPa}$ \\
\hline $35-36$ & Advection of Temperature & $850,700 \mathrm{hPa}$ \\
\hline $37-38$ & Advection of Humidity & $850,700 \mathrm{hPa}$ \\
\hline $39-40$ & Thermal Wind u and v component & $1000 / 850 \mathrm{hPa}$ \\
\hline 41 & Advection Indicator & $1000 / 850 \mathrm{hPa}$ \\
\hline $42-43$ & Thermal Wind u and v component & $850 / 700 \mathrm{hPa}$ \\
\hline 44 & Advection Indicator & $850 / 700 \mathrm{hPa}$ \\
\hline $45-46$ & Thermal Wind u and v component & $700 / 500 \mathrm{hPa}$ \\
\hline 47 & Advection Indicator & $700 / 500 \mathrm{hPa}$ \\
\hline $48-49$ & Pseudopot. Temperature & $1000,850 \mathrm{hPa}$ \\
\hline $50-53$ & $24 h r$ Geopotential Change & $1000,850,700,500 \mathrm{hPa}$ \\
\hline $54-57$ & Isallobaric wind & $1000,850,700,500 \mathrm{hPa}$ \\
\hline 58 & The Sum Predictor & - \\
\hline 59 & Day Length (Hours) & - \\
\hline 60 & Short wave radiation & - \\
\hline
\end{tabular}

"classical" methods would do) but, rather, the magnitude of the linkage between an objectively selected set of predictors and the predictand. The method identifies specific grid points from atmospheric fields as predictors. The predictand is a local meteorological parameter. The method also has elements of the Environment to Circulation strategy (cf. Subsection 1.3) since - at least optionally - it can be set up to describe events occurring at a subset of the stations wherein the subset is determined by way of separating the predictand data series according to the mean values of the predictand. The stages and steps mentioned in the subsections hereafter correspond to the items displayed in Fig. 1.

\subsection{Stage 1: Regression - constructing the building blocks}

At the onset, a regional variable (the predictand) is defined, e.g., the daily mean of the precipitation derived from a number of stations; this could be a regional subset of the stations or an objectively determined subset according to criteria described in Section 4.2.2 and 4.2.3. In this stage, the method strives for an indirect description (or reconstruction) of that regional variable by the values at individual grid points of one large-scale meteorological field, or a combination of grid points of several such fields (the predictors) from the re-analysis data. The method of choice is a screening regression.

\subsubsection{Step 1.1 - Identification of the most relevant field}

A correlation is computed for the predictand time series and each grid point for every one of the members of the pool consisting of fields of the 60 potential predictors (see top right portion of the schematic in Fig. 1) - at each and every grid point $<\mathrm{m}, \mathrm{n}>$ of the predictor field. For the sake of brevity and comprehensibility the fact that it is an individual co-ordinate of the predictor field is implied and not explicitly spelled out in the equations. This yields the first predictor $P_{1}$, i.e., the single most "influential" atmospheric parameter (at co-ordinate $<\mathrm{m}, \mathrm{n}>$ ) for our predictand with the correlation $r_{1}$. For example, the vorticity in $850 \mathrm{hPa}$ at a certain co-ordinate $<\mathrm{m}, \mathrm{n}>$ might be the descriptor featuring the highest correlation with respect to precipitation. Since it is only one predictor which is identified in this stage, $r_{1}$ is a single and not a multiple correlation. When two and more predictors are gradually identified (see Section 3.1.2), this becomes a multiple correlation.

\subsubsection{Step 1.2 - Identification of further relevant fields}

Keeping the first predictor $P_{1}$ found in step 1 in the calculations, a further predictor $P_{2}$ is then identified. The multiple correlation $r_{2}$ of $P_{1}$ in combination with all 59 remaining potential predictors is computed at every grid point. In cases where an $r_{2}>r_{1}$ can be found, the combination $P_{1} \rightarrow$ $P_{2}$ is accepted. If not, $P_{1}$ remains the sole predictor.

This step may be performed several times so that up to four predictors $P_{1} \rightarrow P_{2} \rightarrow P_{3} \rightarrow P_{4}$ are identified, always based on the principle that the predictors from step Q-1 are kept and at step Q the search for a new predictor in combination with the previous one is launched and introduced to the vector of predictors in cases of the correlations being $r_{Q}>r_{Q-1}$.

The upper limit of using four predictors is an empirical threshold which balances a) the gain of information by adding more predictors with $b$ ) the risk of over-fitting and numericalstatistical instability. In fact, the screening regressions that were performed with various predictands never broke off before an identification of four predictors was achieved. 


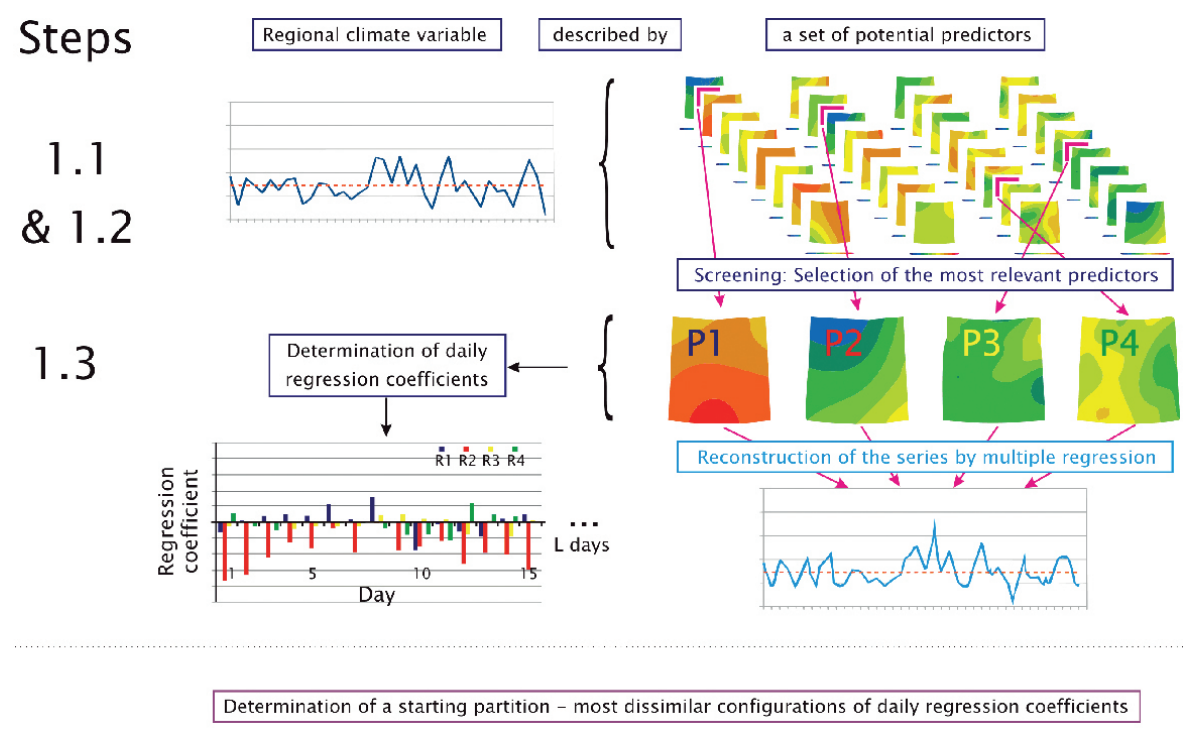

2.1

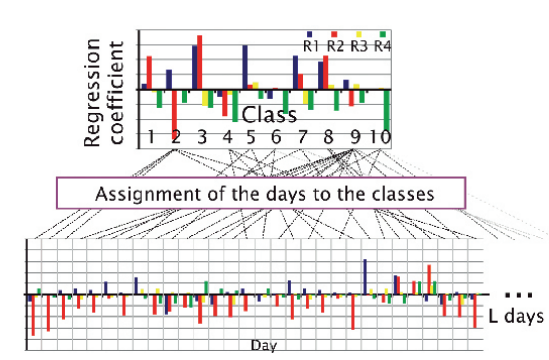

Fig. 1. Schematic of the screening regression and classification method

3.1.3. Step 1.3 - Daily regressions, the source of the patterns

The previous steps identified up to four predictors which indirectly describe the predictand. For each day it is then determined which share the individual predictors contribute to the regression. The regression coefficients $R 1 \ldots R 4$ are factors in the regression equation which are assigned to the predictor fields $P 1 \ldots P 4$ and which are needed to reproduce the predictand. The principle, i.e., the day-to-day configurations of $R 1 \ldots R 4$, is depicted in the bar diagram which is in the left part of the "Step 1.3" segment of Fig. 1. It should be noted that the regression coefficients $R 1 \ldots R 4$ vary in a systematic and smooth way from day to day.

When this is applied to a time series of length $L$, e.g., all days from 1 January 1981 to 31 December 2010, a matrix of $L \times Q(Q:$ number of predictors, at most four) is generated. For each of the $\mathrm{L}$ days $d$ there is a pattern formed by a vector, the components of which are the regression coefficients $R 1_{d} \ldots R 4_{d}$. It is exactly this set of patterns which is analysed in the subsequent stage with the aim of organising them into distinct classes.

\subsection{Stage 2: Classification - identification of similar cases}

The second stage of the method - below the dotted line in the schematic display (Fig. 1) - is a classification. The method of choice is $k$-means clustering. This is an instance of the clustering methods which first generate a starting partition (cf. Subsection 3.2.1) of $N$ maximally dissimilar cases $C_{S P} 1 \ldots C_{S P} N$ and subsequently forms $N$ classes $C 1 \ldots$ $C N$ by assigning the remainder of the cases to their most similar case (cf. Subsection 3.2.2).

There is an optional step (cf. Subsection 3.2.3) in which individual classes are further analysed with respect to structures and dependencies that may have been missed in the initial classification steps, described in Subsection 3.2.3.

The objects to be classified are the individual daily "settings" of the regression coefficients (e.g., in qualitative terms, $R 1>0, R 2<0, R 3>0, R 4=0$, etc.).

\subsubsection{Step 2.1 - Identification of a starting partition}

At first one day $d_{1 s t}$ is randomly selected from the $L$ days in the time series. It has a vector of four regression coefficients $R 1_{d \mid s t} \ldots R 4_{d l s t}$. expressed as $R_{i}\left(d_{1 s t}\right)$ in the equation. Then the day with the most dissimilar vector of four regression coefficients is identified by evaluating:

$$
\sqrt{\sum_{i=1}^{4} \mid R_{i}\left(d_{1 s t}\right)-R_{i}\left(d_{t e s s}\right)} \mid \rightarrow \max
$$

with $i$ : enumerator of the four regression coefficients; $d_{t e s}$ : one of the remaining $L-1$ days to be tested against $d_{1 s t}$ for dissimilarity of the vector of regression coefficients. 
This yields the first member of the starting partition $C_{S P} 1$, which exhibits maximum dissimilarity to the randomly selected day; $C_{S P} 1$ is sometimes also referred to as the first centroid. This procedure is applied $N-1$ times to identify the remaining centroids, yielding a set of cases (ten in the bar diagram which is associated with Step 2.1 in the schematic of Fig. 1).

\subsubsection{Step 2.2 - Assigning cases to the members of the} starting partition

Having generated the set of $N$ centroids, the next task is to test, for each of the $L-N$ days, which of $N$ the centroids has the greatest similarity, i.e., to perform the class assignment for the remaining days - as shown in the bottom row of Fig. 1. This is done by evaluating:

$$
\sqrt{\sum_{i=1}^{4} \mid R_{i}\left(C_{s p} n\right)-R_{i}\left(d_{\text {test }}\right)} \mid \rightarrow \min
$$

with $i$ : enumerator of the regression coefficients; $d_{\text {test }}$ : one of the remaining $L-N$ days to be tested against $C_{s p} n$ for similarity of the vector of regression coefficients and $C_{s p} n: n^{\text {th }}$ centroid.

The evaluation is performed for all $n \in 1 \ldots N$ centroids At the end of the assignment step there is a classification according to the principle of maximal similarity to the centroids of the starting partition. If a class contains 10 or less cases (depending on the desired "extremity" of the classification, the required minimum membership can be set to other values) it is dissolved.

\section{Note 1 - On the building of the starting partition}

In practice, it turned out that additional effects had to be considered. Suppose there is a multi-dimensional cloud of configurations $R_{1} \ldots R_{4}$ for all days, of which at step $m=1$ the first one $d_{1 s t}$ is randomly selected. At step $m=2$ the most dissimilar case to the $m=1$ selection is located at the "opposite end" end of the cloud. Yet, when successively applied, the third case ( $m=3$, by definition most dissimilar to the $m=2$ selection) has a high probability of being located close to the first case again. In other words, there is a kind of "see-saw" in action which yields a suboptimal starting partition. Another effect stems from the question of whether the randomly selected case is really the best possible initialisation of the building procedure. A result-oriented procedure had been devised that addresses both issues:

- In a succession of search processes, every day is used as a tentative starting day $d_{1 s t}$ yielding a tentative starting partition consisting of $N$ (e.g. 10) members.

- For each tentative starting partition the assignment of all remaining days is carried out, yielding $N$ classes with $N_{n}$ members. Moreover, for each class the mean class-specific mean of the predictand $P$ (e.g., the maximum temperature, or the share of stations having experienced thunderstorms or wind gusts, etc.) $\overline{x_{p_{n}}}$ is computed.

- A specific distance measure for the tentative classification $D M_{t}(t$ stands for tentative here) is computed with the aim of checking if the tentatively produced assignment of days to the tentative starting partition leads to a constellation in which all classes are well separated. This is the weighted sum of the deviation of the classspecific averages $\overline{x_{p_{n}}}$ from the average across all classes $\bar{x}$ according to:

$$
D M_{t}=\sum_{n=1}^{N}\left[\left(\overline{x_{n}}-\bar{x}\right)^{2} \cdot N_{n}\right], D M_{t} \rightarrow \operatorname{Max}
$$

- A tentative classification is excluded if classes with too few members (e.g., 10) are produced.

- If, in the light of the latter criterion, no tentative classifications are found, the number of classes $N$ is stepwise reduced by 1 and the procedure is repeated.

Thus, based on numerous attempts, a starting partition is produced that, under the data-specific circumstances, yields a well-separated set of classes using the best possible initial case.

\section{Note 2 - On the exchange procedure in k-means clustering}

The "standard procedure" of the k-means clustering foresees a third step in which iteratively an exchange of cases between classes takes place until a stable state is reached. The reason is that a centroid's position is not fixed in multidimensional space. Rather, with each case added to a centroid its position is recalculated leading to a gradual "trajectory" away from its initial position (see, e.g., Enke, Spekat 1997 for a visualisation of this effect). At the end of the assignment (Step 2.2) this aforementioned centroid drift results in a state in which cluster membership is (i) ambiguous for a subset of the cases and (ii) is not entirely correct, since the cases picked up early in the trajectory might ultimately not be the best match regarding the final position of the centroid.

The exchange step of $k$-means clustering is devised to address this effect. However, in the context of extremes there is an important detrimental side effect: Small classes, as they appear when the initial class assignment (Step 2.2) has taken place, will receive extra cases, which renders them less focused on extremes. Therefore, the exchange step is deliberately not carried out, accepting the risk that the cluster separation is not optimal - an assessment of the effects of this omission showed that the cases that might change class membership are part of rather large clusters that tend to describe the average state and are thus not relevant for the extreme-oriented analyses. 


\subsubsection{Step 2.3 Further within-class structures}

The methodology, once it is applied, evaluates correlations of potential predictors from large-scale atmospheric fields with regional climate parameters. It can be surmised, nevertheless, that more dependencies may be "hidden" and a distinct analysis of cases within an individual class may reveal the usefulness of additional predictors. Therefore, as an option, the method can be applied a second time, but this time restricted to all days belonging to an individual class, yielding "second-order classes". Thus, all the steps described above (screening regression, formation of a start partition, class assignment) would then be carried out for the particular subset of all days gathered in a "first-order class".

It should be added that for reasons of numerical stability this second application of the methodology on an individual class can only be carried out if there are sufficient cases. Experience indicates that the minimum requirement is on the order of 20 members in a class. The method then also applies criteria, explained in Subsection 3.1.2, to constrain the number of "second-order classes". There are rather few of these classes generated, frequently between 2 and 5 , depending on the size of the class that is subjected to this step.

\section{Examples and Discussion \\ 4.1. Screening regression}

So which are the large-scale predictors that are highly correlated with the local predictand? And do they exhibit particularities with respect to the kind of predictand? A few example screenings were carried out (i) for the entire year, the winter and summer half years and the four seasons, which totals 7 time frames and (ii) for stations grouped according to the broad order of magnitude of the predictand (e.g., lowland stations were put together in a group for their temperature and precipitation characteristics; they are different from stations in a more elevated terrain) yielding $7 \times 2$ screenings. Then a scoring system was applied assigning five points to a variable that was put in the first rank (meaning that this predictor out of the pool of potential predictors has the greatest efficiency in describing the predictand). The second rank was assigned three points, the third rank two points and the fourth rank one point. The results are displayed in Table 3 - for brevity's sake, the predictors are not explicitly spelled out in Table 3 but, rather, their reference number (cf. Table 2) is used.

Not surprisingly, relative topography scores high with regional temperature and the description of precipitation depends on incoming radiation (or, rather, lack thereof) as well as gradient and vorticity-related information. The regional behaviour of the predictand vapour pressure is dependent on the lengths of the days, relative topography and several kinds of large-scale humidity information, and the wind has a strong linkage to gradients in the geopotential fields.

In the following section, some examples are given using a selection of meteorological parameters and extreme indicators, though not all of those which are featured in Table 3.

\subsection{Characteristics of the classes generated by the method}

In the following examples, the classification is carried out according only to the method's steps 1.1 through 2.2 described in Subsections 3.1 to 3.2.2. This means that a deeper look into within-class structures (cf. Subsection 3.2.3) is not dealt with. Generally speaking, there is the potential of some extra benefit in terms of the correlation between reconstructed-from-proxies time series and the time series-consisting-of-measurements. However, conveying the method's principle is the main aim of this paper. Moreover, it is envisaged that for many applications a classification on the level described in Subsections 3.1 to 3.2.2 is sufficient.

\subsubsection{Predictand: Maximum temperature}

As an illustrative example, the method was applied to 1971-2010 maximum temperature (TX) data from 36 climate stations in the German Federal State of Hesse. The classification method was then performed - using mainly the $T X$ predictors indicated in Table 3 - for the summer half-year (April-September). Furthermore, the method was conditioned to produce classes with a membership of 10 or more days. This resulted in one class being dissolved, leaving 9 classes. Table 4 presents the characteristics of these classes. Alongside the number of members (days that were assigned to an individual class), the mean, maximum and minimum, and 95 percentile for each class are given. In addition, using the daily settings of the regression coefficients, a "reconstruction" of the $T X$ series was performed. This series has a correlation of 0.82 with the original $T X$ series.

It should be noted that, indeed, rather well defined extreme classes were produced. Classes 2 through 6, in particular, contain either very cold or very warm days, respectively. Classes 1, 7 and 8 represent the average conditions, not the extremes, their membership being $>10 \%$ of all analysed days.

As briefly mentioned in Section 4.1, there is an optional precursor step which applies a clustering procedure to group the climate stations according to the value range of 
Table 3. Scoring of the predictors (enumeration according to entries in Table 2) identified by the screening regression for selected predictands $T X, T N, R R_{\text {all }}$ (at climate and precipitation stations), $R R_{c l i}$ (at climate stations only), DD (daily means) and $F F$ (daily means)

\begin{tabular}{|c|c|c|c|c|c|}
\hline Predictand & Predictor & Score & Predictand & Predictor & Score \\
\hline \multirow{5}{*}{$T X$} & 19 & 62 & & 19 & 56 \\
& 59 & 42 & & 59 & 36 \\
& 58 & 9 & $T N$ & 7 & 15 \\
& 15 & 7 & & $12 / 58$ & 10 \\
\hline \multirow{5}{*}{$R R_{\text {all }}$} & 60 & 23 & & 60 & 21 \\
& 12 & 13 & & 12 & 18 \\
& 16 & 10 & $R R_{\text {cli }}$ & 15 & 9 \\
\hline \multirow{5}{*}{$D D$} & 58 & 6 & & 58 & 6 \\
\hline & 59 & 38 & & 31 & 31 \\
& 19 & 38 & & 30 & 17 \\
& 73 & 22 & $F F$ & 59 & 15 \\
\hline
\end{tabular}

the predictand (here: $T X$ ). If particularly high $T X$ values are aimed for - in essence the stations then are from the lower altitude areas of Hesse (between 90 and $350 \mathrm{~m}$ above sea level) - 25 Stations are selected. Alternatively, the complementary 11 stations, which exhibit lower $T X$ values, can be subjected to the classification. However, concerning the relevant predictors identified by the screening procedure, there are no major differences with respect to those station groups as well as the ungrouped stations. The "mainstays" (e.g., relative topography or the sum predictor) provide the bulk of the information in all cases. There is merely a slight shift towards extracting information from absolute humidity fields at higher altitudes versus having useful contributions by geopotential and vorticity at lower altitudes. The correlations remain at 0.82 throughout.

\subsubsection{Predictand: Probability of exceedance of $T X=30^{\circ} \mathrm{C}$}

The data from the 36 stations are transformed in the following way: For each day of the summer half-years, the percentage of the stations is computed at which a $T X$ $>30^{\circ} \mathrm{C}$ occurred. So a value of 100 means that all stations exhibit the surpassing of this threshold - something that happened only 7 times in the years investigated (19712010). This number of cases increases to 18 if one station is allowed to not surpass $30^{\circ} \mathrm{C}$ (percentage: 97.2 ) and it further increases to 33 if the non-occurrence can be at two stations (percentage: 94.4) and to 53 if three stations are allowed to remain below $T X=30^{\circ} \mathrm{C}$.

The screening multiple regression procedure detects that the highest potential of indirectly describing the time
Table 4. Characteristics of the classes obtained by an analysis of $T X$ in the summer half-year (April to September), applied to 25 lowland stations from the German Federal State of Hesse. Method was forced to retain only classes with $\geq 10$ members

\begin{tabular}{|c|r|r|r|r|r|}
\hline Class & Members & \multicolumn{1}{c|}{ Mean } & Max & \multicolumn{1}{c|}{ Min } & \multicolumn{1}{c|}{ Q } \\
\hline 1 & 979 & 26.8 & 34.4 & 17.1 & 31.3 \\
\hline 2 & 15 & 12.2 & 15.1 & 10.5 & 13.8 \\
\hline 3 & 15 & 32.2 & 37.1 & 29.5 & 34.1 \\
\hline 4 & 37 & 10.0 & 16.2 & 1.0 & 15.2 \\
\hline 5 & 182 & 30.9 & 36.9 & 24.9 & 34.8 \\
\hline 6 & 44 & 12.1 & 16.3 & 1.8 & 15.6 \\
\hline 7 & 554 & 13.7 & 23.1 & 3.7 & 19.1 \\
\hline 8 & 2531 & 22.1 & 31.3 & 8.4 & 27.4 \\
\hline 9 & 2962 & 17.1 & 27.1 & 3.7 & 23.0 \\
\hline
\end{tabular}

series of these percentages for the summer half-year by way of atmospheric properties lies in the relative topography $1000 / 850 \mathrm{hPa}$, the absolute humidity at $700 \mathrm{hPa}$, the day length and vertical temperature difference between the 850 and the $700 \mathrm{hPa}$ level. The multiple correlation coefficient, however, is 0.48 and thus clearly lower as for the predictand $T X$.

Table 5 shows the characteristics of the classes being formed. The first class, containing the vast majority of all days, represents the average conditions, where - in some cases - up to about 30 station may exceed the $T X=30^{\circ} \mathrm{C}$ threshold, yet the mean percentage is much below that. The second class contains a well-defined set of extremely hot days. At least 23 of the 36 stations, often all of them, exhibit the surpassing of the $30^{\circ} \mathrm{C}$ threshold. It is furthermore remarkable that there are three distinct cold classes (nos. 3, 4, and 6) in which the threshold is never surpassed. The fact that these cases are not gathered in one single class is due to the different settings of the regression coefficients that characterise those classes. The remaining classes (nos. 5, 7, and 8) contain a majority of days which have the threshold exceedance at a high fraction of the 36 stations (indicated by the rather high 95-percentile values) but also contain a sizeable number of days where no station showed a $T X>30^{\circ} \mathrm{C}$. Thus, they can be considered ambiguous, i.e., not fully extreme, yet with a tendency of belonging to the high temperature range.

\subsubsection{Predictand: Probability of exceedance of $R R=20 \mathrm{~mm}$}

The data of the 36 climate stations are transformed as follows: First an objective method is used to group the stations into high-precipitation and low-precipitation bins. The selected seven high-precipitation stations are either from altitudes higher than 450 a.s.l. or the rain amounts received are orographically enhanced. Next, for each day 
Table 5. As in Table 4, but for the predictand "probability that $T X>30^{\circ} \mathrm{C}$ " at the 36 climate stations in Hesse

\begin{tabular}{|c|r|r|r|r|r|}
\hline Class & Members & \multicolumn{1}{c|}{ Mean } & \multicolumn{1}{c|}{ Max } & \multicolumn{1}{c|}{ Min } & \multicolumn{1}{c|}{ Q $_{95}$} \\
\hline 1 & 5643 & 0.5 & 86.1 & 0.0 & 0.0 \\
\hline 2 & 13 & 88.5 & 100.0 & 63.9 & 100.0 \\
\hline 3 & 76 & 0.0 & 0.0 & 0.0 & 0.0 \\
\hline 4 & 204 & 0.0 & 0.0 & 0.0 & 0.0 \\
\hline 5 & 99 & 43.2 & 100.0 & 0.0 & 97.2 \\
\hline 6 & 495 & 0.0 & 0.0 & 0.0 & 0.0 \\
\hline 7 & 727 & 16.6 & 97.2 & 0.0 & 77.8 \\
\hline 8 & 61 & 59.4 & 100.0 & 0.0 & 97.2 \\
\hline
\end{tabular}

of the summer half-years, the percentage of the stations is computed at which $R R>20 \mathrm{~mm}$ occurred. So a value of 100 means that all stations exhibited the surpassing of this threshold - something that happened only 13 times in the years investigated (1971-2010). This number of cases increases to 26 if one station is allowed to not surpass 20 $\mathrm{mm}$ /day (percentage: 85.7 ) and it further increases to 33 if the non-occurrence can be at two stations (percentage: 71.4). It should be added that a higher number of these events occur outside the investigated period of the summer half-year, i.e., in the months October through March.

The screening multiple regression procedure detected that the highest potential of indirectly describing the time series of these percentages for the summer half-year by way of atmospheric properties lies in the incoming shortwave radiation, the vorticity at $850 \mathrm{hPa}$, the pseudopotential temperature at $850 \mathrm{hPa}$, and the humidity advection at $850 \mathrm{hPa}$. The multiple correlation coefficient, however, is comparably low, showing a figure of 0.35 . This may be a hint towards the relative "blurriness" of the connection between large-scale atmospheric states and this rather extreme predictand.

Note: If the threshold of $10 \mathrm{~mm} /$ day instead of 20 $\mathrm{mm} /$ day is analysed, the correlation coefficient rises from 0.35 to 0.50 . Moreover, the screening regression picks other predictors (a stability index, and horizontal geopotential gradient-based properties) to contain the most information for an adequate description of that threshold.

Table 6 shows the characteristics of the classes being formed. The first class, containing the vast majority of all days, represents the average conditions. A few of its members have a surpassing of the threshold for all stations $(\operatorname{Max}=100.0 \%)$, but the vast majority have much lower shares of stations meeting this criterion, which is indicated by the 95 -percentile of about $15 \%$. Classes 2 and 5 signify conditions with a tendency to have an $R R$ of more than
$20 \mathrm{~mm} /$ day at a sizeable number of stations, although they do contain days where this threshold was surpassed at none of the 7 stations. However, 95-percentiles above 70\% show that mostly extreme precipitation events are gathered here. On the other hand, classes 3, 4, 7 and 9 isolate cases with comparably rare occurrences of $R R>20 \mathrm{~mm}$. Class 4 in particular shows the surpassing of this threshold appearing at a mere $15 \%$ of all stations, or even less (cf. the "Max" column of Table 6). The rather low 95-percentiles of these classes are a further indicator of this impression. Furthermore there are several classes describing days with a low probability of an $R R>20 \mathrm{~mm} /$ day event occurring, which stems from the fact that these classes are all characterised by different settings of the contributing regression coefficients. Classes 6 and 8 contain cases which have neither a high profile concerning the occurrence of $R R>20 \mathrm{~mm} /$ day nor its non-occurrence.

Note: Using the $R R>10 \mathrm{~mm} /$ day threshold as the predictand, which is surpassed at the entirety of the seven stations much more often (about 90 times in the 40 summer half-years investigated), not only a higher correlation between the describing predictors and the predictand (see above) can be found, but also a better separation of the (not quite so) extreme cases in the classes emerges.

Table 6. As in Table 4, but for the predictand "probability that $R R>20 \mathrm{~mm}$ ", applied to 7 stations at higher elevations in Hesse

\begin{tabular}{|c|r|r|r|r|r|}
\hline Class & Members & \multicolumn{1}{c|}{ Mean } & \multicolumn{1}{c|}{ Max } & \multicolumn{1}{c|}{ Min } & \multicolumn{1}{c|}{$\mathrm{Q}_{95}$} \\
\hline 1 & 5668 & 2.1 & 100.0 & 0.0 & 14.3 \\
\hline 2 & 11 & 23.4 & 100.0 & 63.9 & 71.5 \\
\hline 3 & 209 & 0.9 & 100.0 & 0.0 & 0.0 \\
\hline 4 & 486 & 0.1 & 14.3 & 0.0 & 0.0 \\
\hline 5 & 164 & 22.8 & 100.0 & 0.0 & 85.7 \\
\hline 6 & 36 & 7.5 & 100.0 & 0.0 & 42.9 \\
\hline 7 & 98 & 3.9 & 57.1 & 0.0 & 14.3 \\
\hline 8 & 55 & 7.0 & 57.1 & 0.0 & 42.9 \\
\hline 9 & 592 & 0.4 & 100.0 & 0.0 & 0.0 \\
\hline
\end{tabular}

\subsubsection{Predictand: Randomly ordered days}

This test was carried out to obtain an indication of what connections are identified by pure coincidence. In this example, the TX series of all 36 stations were randomly ordered for the summer half-years 1971-2010. This resulted in a very low correlation coefficient of 0.08 . Table 7 shows that the method, indeed, does produce some variety in the class mean values, as well as the class size. The number of classes is smaller than in all previous examples, though - there is simply not enough differentiation beyond 
Table 7. As in Table 4, but for the predictand " $T X$ ", applied to all 36 stations in Hesse with their time series reshuffled in random order

\begin{tabular}{|c|r|r|r|r|r|}
\hline Class & Members & \multicolumn{1}{c|}{ Mean } & Max & \multicolumn{1}{l|}{ Min } & \multicolumn{1}{c|}{ Q $_{95}$} \\
\hline 1 & 3886 & 13.2 & 36.3 & -12.3 & 26.8 \\
\hline 2 & 2352 & 12.5 & 34.3 & -11.3 & 26.6 \\
\hline 3 & 224 & 14.1 & 36.3 & -4.0 & 27.1 \\
\hline 4 & 52 & 10.8 & 33.3 & -4.0 & 22.4 \\
\hline 5 & 334 & 11.8 & 32.5 & -10.2 & 24.6 \\
\hline 6 & 468 & 12.2 & 32.9 & -9.7 & 26.4 \\
\hline
\end{tabular}

mere randomness to form more classes. However, none of them could earn the label "extreme" at all. They all contain days with $T X>30^{\circ} \mathrm{C}$ as well as days with $T X<-4{ }^{\circ} \mathrm{C}$.

\subsection{Discussion - what can be gained?}

Why all this effort, when extreme days could be identified by simply filtering them out of the time series?

For one, these days are identified by linking them to certain extreme atmospheric conditions. They are collected in the different classes because conditioning factors of the large-scale circulation are similar. Having applied the classification to climate station time series, the user is supplied with rather homogeneous subsets of extreme days, ready to be used in further analyses.

For two, in the actual climate there may be a traceable connection between "real surface measurements" (station data) and "real free atmosphere information" (reanalysis data). But what if climate model projections of future atmospheric states are to be analysed? The regression coefficients are a tool for reconstructing the surface time series - albeit with a variable degree of certainty for different meteorological elements, as the different correlations suggest. It also has to be taken into account that climate models do not capture all atmospheric fields equally well. Temperature and geopotential do not pose major problems, but fields like humidity do. Thus, one must carefully study which fields are picked by the screening as relevant contributors to the regressions to assess the degree of trust in the results. Bearing this in mind, the settings of regression coefficients which are in conjunction with extreme values can be applied to the climate model projections to produce proxies of surface extremes. This leads to the opportunity of studying changes in the frequency and magnitude of extremes. Basically, current climate conditions are the training set for identifying, verifying and validating the connections between the large-scale atmosphere and the regional climate. The modelled future is then used as the application ground.

The method is quite flexible. In principle, any connection between a property at the surface and the large-scale free atmosphere state can be sorted out - provided there is indeed such a connection. The method can be fed, e.g., with a string of $0 \mathrm{~s}$ and $1 \mathrm{~s}$ for a sufficiently long consecutive series of days which mark the non-occurrence or occurrence of thunderstorms, floods, air quality threats and so on. The correlation, i.e., the robustness of the result, may vary, but the fact remains that extremes are put into distinct classes and that they can be inferred from climate projection runs.

\section{Summary and Outlook}

A method has been presented that takes a novel look at structures identified in the large-scale atmosphere and their connection to local meteorological parameters in the context of forming distinct classes. The advantage of applying this method is that some of the classes it produces contain extreme atmospheric conditions and the adjoint extreme conditions at the surface. It can be thus helpful in terms of a way to obtain extreme cases for further studies - in an objective way. It can also be helpful when analysing the future magnitude and frequency of extreme atmospheric conditions and their consequences at the surface, using climate model projections.

The method does not aim at a description of average conditions; it has to be kept in mind that the separation of the predictand though the entirety of the classes which it generates is not optimal. This is a trade-off consequence unavoidable in light of the desire to efficiently focus on the separation of extremes.

In several examples the performance of the method to generate extreme classes for some relevant predictands, such as temperature and precipitation extremes, was shown. There are correlations provided which help assess the robustness of the results and thus the weight they may have for obtaining information on future meteorological extremes, as well as their inclusion in decision making processes.

The authors acknowledge that users (e.g., impact modelers or decision makers) still have numerous requests and requirements. Addressing them requires a constant and ongoing effort. This includes an improved treatment of meteorological extremes.

\section{Acknowledgements}

The data from the climate stations are courtesy of the German Weather Service. NCEP Reanalysis data were provided by the NOAA/OAR/ESRL PSD, Boulder, Colorado, USA, through their website at http://www.esrl.noaa. $\mathrm{gov} / \mathrm{psd} /$. 


\section{Appendix}

\section{A - Description of selected predictors and their compu- tation from atmospheric fields}

Most of the predictors listed in Table 2 are straightforward, accessible and intelligible. For a few, however, the necessity is felt to introduce them in a bit more detail.

\section{A.1. Vorticity}

The property used is the relative vorticity $\zeta$ in geostrophical approximation, computed as $\nabla^{2} \Phi(\nabla$ : nabla operator and $\Phi$ : geopotential). At a grid point $i, j$ ( $i$ in zonal and $j$ in meridional direction) the vorticity is approximated by:

$$
\zeta_{i, j}=-4 \cdot \Phi_{i, j}+\Phi_{i, j-1}+\Phi_{i, j+1}+\Phi_{i+1, j}
$$

\section{A.2. Frontal angle according to Margules}

This property assesses the intensity of precipitation processes caused by dynamic lifting. It is the frontal inclination angle $\alpha$ as described in Margules (1906):

$$
\tan \alpha=\frac{f}{g} \cdot T \cdot \frac{\Delta v}{\Delta T}
$$

with $f$ : Coriolis parameter; $g$; constant of gravity; $T$ : Temperature; $\Delta v$ and $\Delta T$ : difference of the wind velocities or temperature, respectively in the warm and cold air mass.

$\alpha$ can only be approximated and it is common to do so by computing the angle $\gamma$ instead:

$$
\gamma^{\prime}=\frac{f}{g} \cdot T_{v} \cdot \frac{\Delta_{z} v_{y}}{\Delta_{x^{\prime}} T_{v}}
$$

in the $850 \mathrm{hPa}$ level with $\Delta_{x^{\prime}} T_{v}$ denoting the jump in the virtual temperature.

\section{A.3. Lability Index after Showalter}

This index, first devised in Showalter (1947), extracts lability information from temperature and humidity in 850 and $500 \mathrm{hPa}$ :

$$
S I_{S}=T_{500}-T_{P_{500}}
$$

with $T_{500}$ : temperature in $500 \mathrm{hPa}$ and $T_{P_{500}}$ : modified pseudopotential temperature, assuming that an air parcel is lifted dry-adiabatically from $850 \mathrm{hPa}$ to its condensation level and then is lifted further in a wet-adiabatical way.

\section{A.4. Lability Index according to Enke}

This index, first described in Deutschläender and Enke (2004), evaluates geopotential information from 1000, 700 and $500 \mathrm{hPa}$ :

$$
S I_{E}=\Delta T_{f, v}-\Delta_{v} T
$$

with $\Delta v T$ : vertical temperature difference and $\Delta T_{f, v}$ : wet- adiabatical vertical temperature gradient. It requires computing:

$$
\Delta T_{f, v}=T_{f, v_{850}}-\left(T_{850}-\gamma_{f} \cdot \Delta z\right)
$$

with $\Delta z$ : height difference and:

$$
\gamma_{f}=\left(\frac{d T}{d z}\right)_{f}=0.973 \beta\left[\frac{K}{100 m}\right] ; \beta=\frac{p+a}{p+b}
$$

with:

$$
\Delta T_{f}=T_{f_{850}}-\left(T_{850}-\gamma_{f} \cdot \Delta z\right)
$$

with $p$ : air pressure; $a$ and $b$ : empirical constants according to Linke and Baur (1970) and:

$$
\Delta z=z_{600}-z_{850}=\bar{T}_{v} \cdot \frac{R}{g} \ln \left(\frac{850}{600}\right)
$$

with $\bar{T}_{v}$ : Virtual temperature; $R$ : Gas constant.

The layers of 850 and $600 \mathrm{hPa}$ are chosen to approximate the middle of the $1000 / 700$ and the 700/500 level, respectively.

\section{A.5. Advection of temperature and relative humidity}

The horizontal transport (advection) of, e.g., temperature $A(T)$ is expressed by:

$$
A(T)=-\overrightarrow{v_{h}} \cdot \nabla_{h} T
$$

with $\overrightarrow{v_{h}}$ : wind in geostrophical approximation according to the thermal wind equation in Subsection A.7 below.

The advection of absolute humidity (using psychrometrical standard tables/formulae) is determined in an analogous way.

\section{A.6. Advection indicator}

This is a dichotomous parameter which yields a positive value in the case of warm air advection and a negative value in the case of cold air advection.

\section{A.7. Thermal wind}

The thermal wind expresses the height-dependent change of the geostrophical wind $\overrightarrow{v_{g}}$. It requires the computation of the horizontal components of the temperature gradient $u_{g}$ and $v_{g}$ - the vertical component of the temperature gradient is approximated to 0 . We have:

$$
\overrightarrow{v_{g}}=\frac{1}{f} \vec{k} \times \overrightarrow{\nabla_{p}} \Phi
$$

with $f$ : Coriolis parameter; $\vec{k}$ : vertical unit vector and $\Phi$ : Geopotential.

The $u$ - and $v$-components of the thermal wind are computed by:

$$
u_{g}=-\frac{1}{f}\left(\frac{\partial \Phi}{\partial y}\right)_{p} \text { and } v_{g}=-\frac{1}{f}\left(\frac{\partial \Phi}{\partial x}\right)_{p}
$$




\section{A.8 .Pseudopotential temperature}

The pseudopotential temperature describes the amount of latent heat included in an air parcel, i.e., its humidity content. It is based on the principle that a parcel with a (not yet condensated) amount of humidity is lifted to its condensation level - meaning that it is saturated. Subsequently, wet-adiabatical lifting takes place and the released condensation heat is added to the parcel's temperature. Now devoid of water vapour, the parcel is transported down to the reference level of $1000 \mathrm{hPa}$. The pseudopotential temperature is computed as follows:

$$
\theta_{p s}=T_{0} \cdot\left(\frac{1000}{P_{0}}\right)^{\frac{\beta R_{L}}{c_{p}}}
$$

with $T_{0}$ : Initial temperature; $P_{0}$ : Initial air pressure; $R_{L}$ : Gas constant for dry air; $c_{p}$ : specific heat capacity keeping pressure constant.

\section{A.9. Isallobaric wind}

This is a "conceptual motion" in which areas of constant change of air pressure over time are determined, e.g., in the course of 24 hours. Then a balance flow is computed which moves across the isopleths of the air pressure change (another name is the Brunt-Douglas isallobaric wind, c.f. Glickman, 2000) - in physical terms this is a flow that occurs under the conditions of a balance between Coriolis Force and geostrophic wind.

\section{A.10. Sum predictor}

The rationale behind the sum predictor is that there may be cumulative or residual properties of the atmosphere "hidden" in the considered fields, yet accessible through an aggregated approach. To this end, all fields in Table 2 - except nos. 26 to 29 and 58 to 60 - were normalised and composites were formed. As it turned out, this sum predictor is rather frequently selected in the screening regression procedure (cf. Section 3.1).

\section{B - Reconstruction of a predictand by way of regression}

In this example, the daily maximum temperature in the summer season (June-August) for a subgroup of lowland stations has been used as the predictand. The screening yielded the following predictors (in order of relevance): (i) Relative Topography $1000 / 500 \mathrm{hPa}$ at field co-ordinate $[10 ; 10]$, i.e. in the centre of the field with a regression coefficient of 0.2500 ; (ii) Vorticity $850 \mathrm{hPa}$ at field coordinate $[13,9]$, i.e. displaced to the northwest with a regression coefficient of -0.0034 ; (iii) Absolute Humidity $850 \mathrm{hPa}$ at field co-ordinate $[11,10]$, i.e. almost at the centre of the field with a regression coefficient of -0.6021 and (iv) Geopotential $700 \mathrm{hPa}$ at field co-ordinate $[19,4]$, i.e. displaced to the northwest with a regression coefficient of 0.0050. Moreover, the constant term of the regression equation was determined to be -331.4254 . Please note that the predictors mentioned above are not exactly the same as those given in the TX part of Table 3. The reason is that the tabulated predictors have been culled from analyses of different seasons and half-years and therefore represent the overall relevant conditions.

Applying the above coefficients to the values of the four different fields as they occurred on a particular day yielded the following relation:

$$
\begin{aligned}
T X & =-331.43+(1367.83 \cdot 0.25)+(39.03 \cdot\{-0.0034\}) \\
& +(6.45 \cdot\{-0.6021\})+(3163.68 \cdot 0.005)=22.33
\end{aligned}
$$

The true $T X$, as it occurred on that particular day, was $23.2^{\circ} \mathrm{C}$. Thus the regression did not yield a perfect reproduction of $T X$ but an approximation with a residual error of $0,9 \mathrm{~K}$. When the regression equation is applied to a succession of days, the single residual errors vary in magnitude and sign; however, they almost compensate each other.

\section{Bibliography}

Barry R., Perry A., 1973, Synoptic Climatology: Methods and Applications, Methuen, London, 555 pp.

Beck C., Philipp A., 2010, Evaluation and comparison of circulation type classifications for the European domain, Physics and Chemistry of the Earth. Parts A/B/C, 35 (9-12), 374-387, DOI: $10.1016 /$ j.pce.2010.01.001

Cahynová M., Huth R., 2009, Changes of atmospheric circulation in central Europe and their influence on climatic trends in the Czech Republic, Theoretical and Applied Climatology, 96 (1), 57-68, DOI: 10.1007/s00704-008-0097-2

Cramer W., Yohe G.W., Auffhammer M., Huggel C., Molau U., da Silva Dias M.A.F., Solow A., Stone D.A., Tibig L., 2014, Detection and attribution of observed impacts, [in:] Climate Change 2014. Impacts, Adaptation and Vulnerability. Part A: Global and Sectoral Aspects. Contribution of Working Group II to the Fifth Assessment Report of the Intergovernmental Panel on Climate Change, C.B. Field, V.R. Barrios, D.J. Dokken, K.J. Mach, M.D. Mastrandrea, T.E. Bilir, M. Chatterjee, K.L. Ebi, Y.O. Estrada, R.C. Geonova, B. Girma, E.S. Kissel, A.N. Levy, S. MacCracken, P.R. Mastrandrea, L.L. White (eds.), Cambridge University Press, UK, New York, USA, 979-1037

Cuell C., Bonsal B., 2009, An assessment of climatological synoptic typing by principal component analysis and k-means clustering, Theoretical and Applied Climatology, 98 (3), 361373, DOI: 10.1007/s00704-009-0119-8

Dalelane C., Deutschländer T., 2013, A robust estimator for the intensity of the Poisson point process of extreme weather events, Weather and Climate Extremes, 1, 69-76, DOI: 10.1016/j.wace.2013.07.003 
Deutschländer T., Enke W., 2004, Abschlussbericht: Ableitung von Wetterlagen aus großräumigen Zirkulationsmustern zur Identifikation von extremen Witterungsperioden mit Schwerpunkt lang anhaltender Trockenheit und deren Projektion in Klimaszenarien (WEREX III), Tech. Rep. 13-8802.3521/57

Dole R., Hoerling M., Kumar A., Eischeid J., Perlwitz J., Quan X.W., Kiladis G., Webb R., Murray D., Chen M., Wolter K., Zhang T., 2013, The making of an extreme event: putting the pieces together, Bulletin of the American Meteorology Society, 95, 427-440, DOI: 10.1175/BAMS-d-12-00069.1

Dzerdzeevskii B.L., 1963, Fluctuations of General Circulation of the Atmosphere and Climate in the Twentieth Century, Changes of Climate, 20, 285-296

Eade R., Hamilton E., Smith D.M., Graham R.J., Scaife A.A., 2012, Forecasting the number of extreme daily events out to a decade ahead, Journal of Geophysical Research: Atmospheres, 117 (D21), DOI: 10.1029/2012JD018015.

Enke W., Schneider F., Deutschländer T., 2005, A novel scheme to derive optimized circulation pattern classifications for downscaling and forecast purposes, Theoretical and Applied Climatology, 82, 51-63, DOI: 10.1007/s00704-004-0116-x

Enke W., Spekat A., 1997, Downscaling climate model outputs into local and regional weather elements by classification and regression, Climate Research, 8 (3), 195-207, DOI: 10.3354/ cr008195

Gerstengarbe F., Werner P., 2005, Katalog der Großwetterlagen Europas 1881-2004 nach P. Hess und H. Brezowsky, PIK Report 100, Potsdam Institute for Climate Impact Research, http://www.pik-potsdam.de/research/ publications/pikreports/files/pr100.pdf (access date 01.04.2016)

Glickman T. (ed.), 2000, Glossary of Meteorology, 2nd Edition, American Meteorological Society, Boston, MA, 850 pp.

Hamilton E., Eade R., Graham R.J., Scaife A.A., Smith D.M., Maidens A., MacLachlan C., 2012, Forecasting the number of extreme daily events on seasonal timescales, Journal of Geophysiccal Research: Atmospheres, 117 (D3), 1-13, DOI: 10.1029/2011JD016541

Hess P., Brezowsky H., 1952, Katalog der Großwetterlagen Europas (Catalog of the European Large Scale Weather Types), Berichte d. Deutschen Wetterdienstes in der US-Zone, 33, Bad Kissingen, Germany

Huth R., Beck C., Philipp A., Demuzere M., Ustrnul Z., Cahynová M., Kyselý J., Tveito O., 2008, Classification of atmospheric circulation patterns: recent advances and applications, Annals of the New York Academy of Sciences, 1146, 105-152, DOI: 10.1196/annals.1446.019

IPCC, 2014, Summary for policymakers, [in:] Climate Change 2014. Impacts, Adaptation and Vulnerability. Part A: Global and Sectoral Aspects. Contribution of Working Group II to the Fifth Assessment Report of the Intergovernmental Panel on Climate Change, C.B. Field, V.R. Barrios, D.J. Dokken,
K.J. Mach, M.D. Mastrandrea, T.E. Bilir, M. Chatterjee, K.L. Ebi, Y.O. Estrada, R.C. Geonova, B. Girma, E.S. Kissel, A.N. Levy, S. MacCracken, P.R. Mastrandrea, L.L. White (eds.), Cambridge University Press, United Kingdom and New York, NY, USA, 1-32

Kalnay E., Kanamitsu M., Kistler R., Collins W., Deaven D., Gandin L., Iredell M., Saha S., White G., Woollen J., Zhu Y., Leetmaa A., Reynolds R., Chelliah M., Ebisuzaki W., Higgins W., Janowiak J., Mo K., Ropelewski C., Wang J., Jenne R., Joseph D., 1996, The NCEP/NCAR 40-Year Reanalysis Project, Bulletin of the American Meteorological Society, 77, 437-471, DOI: 10.1175/1520-0477(1996)077<0437:TNYRP $>2.0 . \mathrm{CO} ; 2$

Klein Tank A., Zwiers F., Zhang X., 2009, Guidelines on Analysis of extremes in a changing climate in support of informed decisions for adaptation, WMO-TD No. 1500, Climate Data and Monitoring WCDMP-No. 72, http://eca.knmi.nl/ documents/WCDMP_72_TD_1500_en_1.pdf (access date 01.04.2016)

Kreienkamp F., Baumgart S., Spekat A., Enke W., 2011a, Climate signals on the regional scale derived with a statistical method: relevance of the driving model's resolution, Atmosphere, 2 (2), 129-145, DOI: 10.3390/atmos2020129

Kreienkamp F., Spekat A., Enke W., 2009, Sensitivity studies with a statistical downscaling method - the role of the driving large scale model, Meteorologische Zeitschrift, 18 (6), 597-606, DOI: 10.1127/0941-2948/2009/0410

Kreienkamp F., Spekat A., Enke W., 2011b, KLIWETT Klimawandel und Wetterlagen Bericht Phase I. Im Auftrag des Sächsischen Landesamtes für Umwelt, Landwirtschaft und Geologie, Dresden, Vergabe B 316, (in German)

Kreienkamp F., Spekat A., Enke W., 2014, Statistische Abschätzung zukünftiger Starkregen- und Starkwindereignisse. Endbericht, Climate and Environment Consulting Potsdam GmbH im Auftrag des Hessisches Landesamt für Umwelt und Geologie, Fachzentrum Klimawandel, Wiesbaden (in German)

Lamb H., 1972, British Isles weather types and a register of daily sequence of circulation patterns, 1961-1971, Geophysical Memorial, Stationery Ofice Books, 88 pp.

Linke F., Baur F., 1970, Meteorologisches Taschenbuch. Neue Ausgabe, Band II. 2. Auflage, Akademische Verlagsgesellschaft Geest \& Portig KG

MacQueen J., 1967, Some methods for classification and analysis of multivariate observations, [in:] Proceedings of the $5^{\text {th }}$ Berkeley Symposium on Mathematical Statistics and Probability, L. LeCam, J. Neyman (eds.), University of California Press, Berkeley, California, USA, 281-297

Margules M., 1906, Über Temperaturschichtung in stationär bewegter und in ruhender Luft, Meteorologische Zeitschrift, $23,243-254$ 
Pepler A.S., Diaz L.B., Prodhomme C., Doblas-Reyes F.J., Kumar A., 2015, The ability of a multi-model seasonal forecasting ensemble to forecast the frequency of warm, cold and wet extremes, Weather and Climate Extremes, 9, 68-77, DOI: 10.1016/j.wace.2015.06.005

Philipp A., Bartholy J., Beck C., Erpicum M., Esteban P., Fettweis X., Huth R., James P., Jourdain S., Kreienkamp F., Krennert T., Lykoudis S., Michaelidis S., Pianko-Kluczyńska K., Post P., Alvaraz D.R., Schiemann R., Spekat A., Tymvios F., 2010, Cost733cat - A database of weather and circulation type classifications, Physics and Chemistry of the Earth. Parts A/B/C, 35 (9-12), 360-373, DOI: 10.1016/j.pce.2009.12.010
Showalter A.K., 1947, A stability index for forecasting thunderstorms, Bulletin of the American Meteorology Society, 34, 250-252

Spekat A., Kreienkamp F., Enke W., 2010, An impact oriented classification method for atmospheric patterns, Physics and Chemistry of the Earth. Parts A/B/C, 35 (9-12), 352-359, DOI: 10.1016/j.pce.2010.03.042

Svensson C., Jones D.A., 2010, Review of rainfall frequency estimation methods, Journal of Flood Risk Management, 3 (4), 296-313, DOI: 10.1111/j.1753-318X.2010.01079.x

Yarnal B., 1993, Synoptic climatology in environmental analysis: a primer, Belhaven Press, London, UK, 195 pp. 